\section{Millions at risk as big cities grow apace in earthquake zones}

Sir - The recent earthquakes in Taiwan, Turkey and Greece are a reminder that the world's urban population is increasingly vulnerable to earthquakes. About onethird of the world's supercities - those with populations of more than two million — are located near tectonic plate boundaries, where damaging earthquakes have occurred and will recur.

Between 1950 and 2050 the world's population will have increased from 2.5 billion to 8.9 billion, most of whom will live in great cities. In 1950 there were two megacities with populations of more than eight million, whereas there are now 27. All cities close to plate boundaries, and many that are not, are vulnerable to earthquake damage some time during the next millennium. Although earthquakes with more than a million fatalities have not occurred in human history, the availability of many new urban targets with populations approaching tens of millions makes such an event possible during the next century.

Offsetting this bleak view of potential fatalities is the recognition that the additional three billion people anticipated in the next 50 years will require a 50 per cent increase in urban construction. Although half of this future growth is expected in parts of Africa where earthquakes are fortunately rare, much future growth is expected in Asia where rates of seismic activity are high. Loss of life from future earthquakes could be much reduced if new construction in known seismogenic zones was designed to withstand shaking.

The reconstruction costs following an urban earthquake have risen to levels that represent an economic burden not only on local economies, but also on the global economy, making the incorporation of earthquake resistance economically attractive.

The absence of earthquake resistant construction in future cities would be indefensible. But the issue may remain a low priority in many developing nations. Roger Bilham

Department of Earth Sciences, University of Oxford, Parks Road, Oxford OX1 3PR, UK

\section{Where are the high-tech entrepreneurs?}

Sir - Craig Pickering argues that a culture of venture capitalism must be created in Europe (Nature 401, 209-210; 1999). I do not believe that lack of government support or venture capital is the reason for the undynamic high-technology landscape, in Germany at least. The problem is a lack of entrepreneurial spirit.

As someone who has recently founded a company with initial finance of almost DM15 million (US\$8.2 million), my impression is that there is hardly a country where start-up venture capital is so easily accessible as it is here - it is much easier to obtain in Germany than in the United States.

At capital fairs, such as the recent Innovation Days in Berlin, there are dozens of banks and venture capital companies exhibiting but hardly any would-be entrepreneurs. The impression left is one between ridiculous and pathetic.

Germany frequently has publicly organized business plan competitions. And the government understands the overwhelming importance of high technology for the future of the economy. Politicians here are showing enthusiasm and respect for high-technology entrepreneurship.

The European problem cannot be solved by just money or political support. It is a problem of culture. I began to develop the vision for my company eight years ago. A feasible scientific concept evolved during my undergraduate and $\mathrm{PhD}$ studies. What was needed was a constant belief that at some point a business would be made out of all this. Once the money seemed available, I was well prepared to jump at it. You need to wish to be an entrepreneur over years of your scientific career. But few Europeans grow up with the desire to found their own businesses. Now that everybody tells them to do so, they neither have the heart nor mature enough ideas.

We Europeans must hope that being a venture capitalist in Europe is not so frustrating that private equity sources will have dried up once today's - hopefully more entrepreneurial - generation of students tries to commercialize its ideas.

Alexander Olek

Epigenomics,

Kastanienallee 24, 10435 Berlin, Germany

\section{The birth of Big Biology}

Sir - Your editorial "Big Science comes of age"l suggests that, in my writings of 40 years ago, I neglected Big Biology. On the contrary, I argued that "We are entering an age of biomedical science and biomedical technology that could rival in magnitude and richness the present age of physical science and physical technology"2.

In arriving at this view I was much influenced by the biologist-cum-engineer Norman G. Anderson, the inventor of the zonal centrifuge. Anderson proposed what he called the Molecular Anatomy programme $\mathrm{e}^{3}$ - cataloguing and characterizing the 100,000 or so human proteins. Part of Anderson's programme was undertaken at Oak Ridge National Laboratory, but a serious, systematic effort has had to await the success of the Human Genome Project (which, incidentally, he had also proposed). Both projects represent Big Biology; both owe much to Anderson's prescience.

\section{Alvin M. Weinberg}

Oak Ridge Associated Universities, PO Box 117, Oak Ridge, Tennessee 37831-0117, USA

1. Nature 400, 387 (1999)

2. Weinberg, A. M. Minerva IV, 5-14 (1965).

3. Anderson, N. G. Science Journal January, 1-7 (1967).

\section{Corot would put more planets in the picture}

Sir-Declan Butler reports on the difficulties the French satellite Corot is facing owing to budgetary reductions (Nature 401, 202; 1999). This report is mainly correct, but I must respond to comments made by David Hughes and cited in the report.

According to the report, Hughes argues that "extrasolar eclipses are rare, even when one is looking at 6,000 stars" and that "by definition, an eclipse would also be irreproducible".

These comments are inappropriate for the following reasons. First, Corot will observe at least 30,000 stars, not 6,000, as there will be five target fields, each observed for 150 days, and each with a required minimum of 6,000 stars. The exact number depends on the density of stars in the chosen target fields and could increase by up to $5 \times 10,000$.

Second, ground-based detection of extrasolar planets has shown that at least three to five per cent of stars have giant planet companions. The geometrical probability of having an eclipse by a planet closer than $0.3 \mathrm{AU}$ is 1.5 per cent. So, over five samples of 6,000 stars, and assuming a similar planet/star ratio to that applied to terrestrial planets, Corot should detect a total of 13 to 22 such planets.

Third, a planet with an orbital period of less than 50 days would, in general, make at least three eclipses in each 150-day run, making them, "by definition", reproducible.

Finally, single-eclipse events will also be analysed, thanks to the two-colour system implemented on the exoplanet channel, which will help reduce false alarms. About ten such events could be detected in this way. Annie Baglin

Corot Team, DESPA,

Observatoire de Paris,

5 place J. Janssen, 92195 Meudon, France 